\title{
Biodegradation of aflatoxin-B1 and zearalenone by Streptomyces sp. collection
}

\author{
Péter Harkai, István Szabó*, Mátyás Cserháti, Csilla Krifaton, Anita Risa, Júlia Radó, \\ Adrienn Balázs, Kinga Berta, Balázs Kriszt \\ Department of Environmental Safety and Ecotoxicology, Institute of Aquaculture and Environmental Safety, Szent István University, 1 Páter Károly St \\ Gödöllö 2100, Hungary
}

\section{A R T I C L E I N F O}

\section{Article history:}

Received 17 September 2015

Received in revised form

9 December 2015

Accepted 9 December 2015

Available online $\mathrm{xxx}$

\section{Keywords:}

Mycotoxin

Aflatoxin B1

Zearalenone

Streptomyces

Biodegradation

\begin{abstract}
A B S T R A C T
Aflatoxin B1 (AFB1) and zearalenone (ZON) are hazardous mycotoxins. AFB1 has cytotoxic, mutagenic and carcinogenic effects, whereas ZON can disrupt the endocrine system. Biodegradation by microbes is an effective method to eliminate these hazardous toxins. The aim of this work was to screen AFB1 and ZON biodegrading potential of one hundred and twenty-four Streptomyces strains deposited in the Actinomycetes strain collection of the Department of Environmental Safety and Ecotoxicology. Two different biotests were used for screening purposes: SOS-Chromotest was used to monitor genotoxicity and select microorganisms with the best AFB1 degrading potential. Estrogenic effect of ZON was measured with a yeast based bioluminescent test including human estrogen receptors Bioluminescent Yeast Estrogen System (BLYES). Biodegradation experiments were conducted with $1 \mathrm{mg} \mathrm{l}^{-1}$ AFB1 and $1 \mathrm{mg} \mathrm{l^{-1 }}$ ZON concentration. On the base of the results, ten strains were selected for biodegradation experiments and Enzyme-linked Immunosorbent Assay tests (ELISA). The results of these tests Streptomyces cacaoi subsp. asoensis (K234) strain degraded AFB1 over 88 per cent and totally eliminated genotoxicity. Two strains of Streptomyces rimosus (K145, K189) degraded almost total amount of ZON and estrogenicity was not detected besides that.
\end{abstract}

() 2015 Elsevier Ltd. All rights reserved.

\section{Introduction}

The worldwide contamination of foods and feeds with mycotoxins is a significant agricultural and medical problem (Hussein and Brasel, 2001). Some fungal species (e.g. Aspergillus spp., Fusarium $s p$.) thrived on cereal plants produce toxins as secondary metabolites (Kurtzman et al., 1987). These complex molecules are highly resistant against physical and chemical impacts, therefore, after harvest, they get easily into animal or human body. Mycotoxins have potential mutagenic, carcinogenic, teratogenic, cytotoxic and immun-modulating effects (Sharma, 1993) therefore, these secondary metabolites are hazardous for animal and human health and they cause serious economic losses in food and feed industry. Two of the most dangerous and common mycotoxins are aflatoxin B1 (AFB1) and zearalenone (ZON) (Wu, 2004). AFB1 has cytotoxic, mutagenic and carcinogenic effects, whereas ZON can disrupt the endocrine system as it can mimic the effect of estrogens

\footnotetext{
* Corresponding author.

E-mail address: Szabo.istvan@mkk.szie.hu (I. Szabó).
}

(Hughes et al., 1991; McLean and Dutton, 1995; Withanage et al., 2001).

"Aflatoxins" are furano-coumarins and compose the most widely studied mycotoxin group, including AFB1 (Williams et al., 2004). This mycotoxin is produced mostly by Aspergillus flavus fungal species (Bennett and Klich, 2003). In birds and mammals, AFB1 reacts with cytochrome $\mathrm{P} 450$ yielding the highly reactive AFB1 8,9-epoxide (Eaton et al., 1994). AFB1 8,9-epoxide inhibits transcription interacting with DNA and that causing cytotoxic, mutagenic and carcinogenic effects. Glutathione transferase (GST) enzymes inactivate epoxides in some livestock animals (e.g. sheep) but there are some exceptions (e.g. poultry) (Bennett and Klich, 2003; Mishra and Das, 2003).

ZON (resorcyclic acide lactone) is one of the most effective nonsteroidal estrogenic mycotoxin produced by some field and storage fungal species, as Fusarium graminearum and Fusarium culmorum (Tanaka et al., 1988). This secondary metabolite might have important role in competition between different fungal species through its fungicid effects (Utermark and Karlovsky, 2007). In addition, beyond its hormonal activity, possible carcinogenic and 
immunotoxic effects were verified as well (Berek et al., 2001; Ehrlich et al., 2002). ZON getting into human and animal body may cause early sexual maturity, miscarriage, underdeveloped embryos (Bennett and Klich, 2003; Farnworth and Trenholm, 1983; Green et al., 1990). ZON is a common contaminant in maize and hay, therefore, elimination of this mycotoxin is an important object in agricultural detoxification (Sun et al., 2014).

To date, there are many methods to destroy mycotoxins like applying ozone (Lemke et al., 1998) or ammonia (Park, 1993). The most frequent method is adding mycotoxin-binding absorbents (e.g. yeast cell wall) to contaminated feed (Ramos et al., 1996). Also biodegradation is a promising method in elimination of mycotoxins since some of microbial species are able to use them as resource of energy. In some animal feed supplement, Trichosporon mycotoxinivorans was used to degrade ZON (Molnar et al., 2004) but this bacterium is not proposed for the EPSA QPS 2013 list (Panel, 2013). For instance, there are some results about Mycobacterium fluoranthenivorans (Hormisch et al., 2004) and Rhodococcus erythropolis (Teniola et al., 2005) related to their potent of aflatoxindegradation. AFB1-degrading bacteria may be aromatic ringdegrading microbes (Cserháti et al., 2013; Krifaton et al., 2011). ZON degradation was reported to be successful using several Rhizopus strains (Varga et al., 2005), the Pseudomonas putida ZEA-1 strain (Altalhi, 2007), the Rhodococcus pyridinivorans (K408) strain (Kriszt et al., 2012) and some Streptomyces and Rhodococcus strains (Krifaton et al., 2013).

Biodegradation methods have risks as well. During decomposition reactions, unknown and harmful by-products might be created which are able to react with other metabolites creating uncontrollable mixture of reagents. Therefore, besides monitoring mycotoxin degradation by immunochemical or other analytical methods, it is very important to develop applicable methods to detect hazardous metabolites producing during mycotoxin biodegradation. According to the published information BLYES (Bioluminescent Yeast Estrogen System; Krifaton et al., 2013), SOSChromotest (Krifaton et al., 2011) and ELISA (Cserháti et al., 2013) are possible applicable methods for biological monitoring of degradation.

Actinomycetes are one of the most important prokaryotic group in biotechnology. They are generally used in industrial enzyme producing (hydrolase, transferase and esterase enzymes) and in pharmaceutical industry since they produce a high variety of antibiotics, antifungal, antiviral and anticancer agents. By far the most successful genus in this group is Streptomyces with over five hundred species. Several successful experiments have been conducted with them about their antagonist effects on mycotoxin producing fungi. Some Streptomyces strains extracted from the Saharan soil were detected to reduce disease symptoms on barley seedlings caused by Fusarium culmosum (Yekkour et al., 2012). Streptomyces (MRI142) strain produced the aflastatin A, which prevented effectively the biosynthesis of aflatoxin produced by Aspergillus parasiticus (Sakuda et al., 1996). This fungus species was also revealed to be inhibited by the Streptomyces sp. (ASBV-1) and in addition, the strain was able to prevent aflatoxin production (Zucchi et al., 2008). Furthermore, several strains like Streptomyces griseus (ATTC 13273) and Streptomyces rutgersensis (NRRL-B 1256) were able to degrade zearalenon mycotoxin directly (El-Sharkawy and Abul-Hajj, 1987). However, the loss of estrogenicity was not detected in any case.

The aim of the present work was the molecular taxonomic classification of the culture collection of Actinomycetes at the Department of Environmental Safety and Ecotoxicology; moreover to select the most effective Streptomyces strains for AFB1 and ZON biodegrading. In our study, degradation was monitored analytical and biological methods, to determine the loss of toxin concentration and the genotoxic or estrogenic effects of metabolites (biodetoxification) as well.

\section{Materials and methods}

The Actinomycetes strain collection was identified by 165 rDNA sequencing, and these classified Streptomyces strains were screened to get information about their ability to degrade two mycotoxins, AFB1 and ZON. As a first step Streptomyces strains were screened in a bitoxin degradation system to make a selection of the most effective (biodegrading) strains. Afterwards the ten most promising strains were analyzed in monotoxin systems also. During this screening method, biological effect of metabolites was monitored: AFB1 degradation potential was measured with SOS-Chromotest, ZON degradation was measured by BLYES. In case of monotoxin systems, toxin degradation was measured by ELISA. In previous reports, ELISA was proved to be a perfect tool for measure toxin concentrations and high correlation was detected with HPLC in measuring ZEA and AFB1 Cserháti et al., 2013; Krifaton et al., 2011).

\subsection{Screening of mycotoxin degradation by Streptomyces strains}

\subsubsection{The strains}

One hundred and twenty-four Streptomyces strains were used to the experiment (one hundred and twenty-three different species but two strains within Streptomyces rimosus). Strains were isolated from soil, decaying plant parts, peat moss and compost samples and identified by the Department of Environmental Safety and Ecotoxicology (Szent István University, Hungary).

\subsubsection{Preparation of the strains}

The strains were cultured on solid LB agar plate (stored at $-80^{\circ} \mathrm{C}$ ) and incubated for 3 days on $28^{\circ} \mathrm{C}$. $30 \mathrm{ml}$ liquid LB media were inoculated by single colonies and incubated for $72 \mathrm{~h}$ at $28^{\circ} \mathrm{C}$, $170 \mathrm{rpm}$. Cell density were adjusted to OD600 $=0.6$ (optical density at $600 \mathrm{~nm}$ wavelength) with IMPLEN SpectroPhotometer (Thermo Fischer Scientific, GENESIS 10S).

\subsubsection{Bitoxin experiment}

In bitoxin experiment the ability of microbes were screened to degrade $1 \mu \mathrm{g} \mathrm{ml}^{-1}$ AFB1 and ZON. Stock solutions were prepared from $1 \mathrm{mg} 99.5$ per cent pure, dry compounds of both mycotoxins (AFB1 and ZON) dissolved in $1 \mathrm{ml} 98.8$ per cent acetone (Sigma-Aldrich, no.: 650501) in ratio 1:1. $0.05 \mathrm{ml}$ toxin stock and $4.95 \mathrm{ml}$ inoculum (OD600) were added into $45 \mathrm{ml}$ liquid LB medium (300 ml Erlenmeyer flask), so the final volume was $50 \mathrm{ml}$. Thus the final concentrations of the two toxins were adjusted to $1 \mathrm{ppm}$. Every flasks were inoculated with $5 \mathrm{ml}$ of the preparated Streptomyces strains. $50 \mathrm{ml} \mathrm{LB}$ medium with $0.05 \mathrm{ml} \mathrm{AFB1/ZON}\left(1 \mu \mathrm{g} \mathrm{ml}^{-1}\right)$ were used as controls. In bitoxin analysis, only control was carried out in triplicates. Flasks were incubated for 5 days at $28^{\circ} \mathrm{C}, 170 \mathrm{rpm}$. $1 \mathrm{ml}$ samples were removed from flasks and centrifuged for $20 \mathrm{~min}$ at $4{ }^{\circ} \mathrm{C}$ and $14,000 \mathrm{rpm}$. Supernatant and pellet were separated and stored at $-20{ }^{\circ} \mathrm{C}$. For monitoring decreased genotoxicity and estrogenisity, SOS-Chromotest and BLYES were applied.

\subsubsection{Monotoxin experiment}

Based on bitoxin experiments, ten Streptomyces strains were selected for monotoxin experiment, where AFB1 and ZON degradation were analyzed individually. The experimental design was the same as the bitoxin systems except for the following differences. Final concentrations of the two toxins were adjusted to $1 \mathrm{ppm}$. Biological effects of supernatant were tested with SOSChromotest and BLYES. Amount of remained toxins were measured with ELISA. For the most effective strains, three parallel ELISA were measured. 


\subsection{The applied biotests for screening biological effect of residue toxins}

\subsubsection{SOS-Chromotest for analyzing the biological effect of AFB1 residue}

SOS-Chromotest is a colorimetric assay, which uses the mutant Escherichia coli PQ37 strain to detect genotoxic and cytotoxic molecules like AFB1 mycotoxin. Genotoxic compounds induce an SOS repair system in $E$. coli bacteria. The structutal of $\beta$-galactosidase is under the control of the sfiA gene, which structural product is recquired for the SOS-response. Thus $\beta$-galactosidase production is an answer for the increasing genotoxicity, so indirectly to the toxin concentration. Adding the proper substrate to the system, the concentration of the enzyme is detectable with colorimetric methods. In our study SOS-Chromotest (Environmental BioDetection Products Inc., Canada) was performed accurately according to Krifaton et al. (2011). The assay was conducted on a white, sterile, flat bottom, 96-well micro-titer plate (Grenier Bioone) on which enzyme activities could be measured photometrically. Negative control contained $10 \mu 110$ per cent DMSO (dimethyl sulfoxide) in saline: $9 \mathrm{~g} \mathrm{NaCl}$ and $100 \mathrm{ml}$ DMSO in $1 \mathrm{l}$ distilled water) and positive controls contained 4-nitroquinoline 1-oxide (4$\mathrm{NQO}$ ) in two-fold serial dilutions.

Induction factors (IF) that are indicative for genotoxicity were calculated by use of the following formula:

$\mathrm{IF}=(\mathrm{A} 405 \mathrm{nc} \times \mathrm{A} 620 \mathrm{t})(\mathrm{A} 405 \mathrm{t} \times \mathrm{A} 620 \mathrm{nc})$,

where ' $\mathrm{nc}$ ' is the negative control and ' $\mathrm{t}$ ' is the test sample. A405 and A620 are the absorbance level at 405 and $620 \mathrm{~nm}$ wave length, respectively. If the induction factor is 1.5 or more the value corresponds with genotoxicity. To validate the results provided by the SOS-Chromotest, a SOS-inducing potency (SOSIP), i.e. the slope of the dose-response curve, was calculated for the positive control $4 \mathrm{NQO}$.

\subsubsection{BLYES for analyzing the biological effect of $Z O N$ residue}

The BLYES was developed by Sanseverino et al. (2005). The genetically modified 'BLYES' strain of Saccharomyces cerevisiae (The University of Tenessee, Knoxville) emits biolumiscence due to estrogenic molecules, like ZON. The BLYES uses this phenomenon to detect estrogenic effect. Intensity of bioluminescence increases in the presence of estrogenic molecules. This test was performed according to the methods and quantities used by Krifaton et al. (2013). For data analysis, bioluminescence was determined with an inverse formula of Froehner et al. (2002) using bioluminescence intensification, instead of inhibition, as follows:

$$
\begin{aligned}
\mathrm{BI} & =\text { Bioluminescence intensification (per cent) } \\
& =-1 \times[(\mathrm{C}-\mathrm{S}) 100 / \mathrm{C}]
\end{aligned}
$$

where ' $C$ ' is the arithmetic mean of the bioluminescence values of parallel negative controls after the incubation time and ' $\mathrm{S}$ ' represents the bioluminescence average value of samples, determined at the time of contact.

In our study $S$. cerevisiae strains BLYES were stored at $-80^{\circ} \mathrm{C}$ and were grown overnight at $30^{\circ} \mathrm{C}$ and $200 \mathrm{rpm}$ to an OD600 of 0.1 in a modified minimal medium (YMM) (Routledge and Sumpter, 1996). BLYES were carried out by placing $20 \mu \mathrm{l}$ of samples from the degradation experiments into the appropriate wells of white, sterile flat bottom, 96-well micro-plate (Greiner Bio-one $\mathrm{Gmbh}$, Germany). Subsequently, $200 \mu$ l of cultures (BLYES and BLYR) were placed into each well, respectively. Bioluminescence was measured at the end of the process after $5 \mathrm{~h}$ in a VictorX Multilabel Plate Reader (Perkin Elmer Inc, US).

\subsubsection{ELISA for toxin degradation analyses in monotoxin systems}

In monotoxin system, in parallel to the above presented biological methods, remaining toxin concentration was determined by Enzyme-linked immunosorbent assay (ELISA) using TOXIWATCH system (SoftFow Biotechnology Ltd., Hungary) according to the manufacturer's instructions. In TOXIWATCH ELISA Kits, methanol (9.4per cent) is used for toxin extraction.

Cultures were grown in LB media in every case. Measurements were carried out in two steps. In the first step, the triplicates of degraded monotoxin systems were mixed to use it as a single sample with an average concentration in ELISA. In the second step, the best degraders were confirmed by repetitive measurements, samples in triplicate were tested by ELISA.

\subsubsection{Absorbance of mycotoxins on the cell wall}

Absorption of mycotoxins on the cell wall may cause the decrease of toxin concentration, but cannot be attributed to biodegradation.

For excluding the probability of absorbance of AFB1 and ZON molecules on bacteria cell wall, pellets from degradation experiments that contained the cells were also analyzed with ELISA method in the case of strains with the most effective degradation. Before degradation tests, toxins were eluted with methanol.

Moreover, structure of ZON molecule is very effective in binding to the cell wall, which may be a stronger bound than extraction with methanol could break. For that reason, ZON binding to the Streptomyces cell wall was tested by inactive cells. The control systems contained the growth medium (LB) and mycotoxins, whereas heat inactivated (autoclaved) cells in the LB also contained the mycotoxins. Loss of estrogenicity in the supernatant was tested by BLYES. Experimental settings were the same as for the monotoxin system except for the incubation was for $12 \mathrm{~h}$ at $28{ }^{\circ} \mathrm{C}$, $170 \mathrm{rpm}$.

\section{Results}

\subsection{Toxin degradation screening by bitoxin degradation}

Bitoxin degradation experiments were conducted to screen the degradation ability of the one hundred and twenty-three Streptomyces species. According to the results of above presented SOSChromotest and BLYES, 68 strains were effective for AFB1 degradation and 27 strains were effective for ZON degradation (see Appendix A). The values of induction factor by SOS Chromotest (less than 1.5) indicated the elimination of toxic effect of AFB1. Elimination of estrogenic effect of ZON was indicated by bioluminescence decline of BLYES (values decreased under 100). Afterwards ten of the most effective Streptomyces strains in the bitoxin method were selected for detailed monotoxin degradation experiments (see Appendix A).

\subsection{AFB1 biodegrading potential by the results of monotoxin degradation method}

Mean induction factor of control samples was 2.25, high genotoxicity was detected due to the lack of AFB1 degradation (Table 1). All strains had lower genotoxicity than the control except for strains Streptomyces baarnensis and Streptomyces spiroverticillatus (K136 and K128). The strains Streptomyces cacaoi subsp.asoensis (K234) could cease genotoxicity. Results of ELISA (Table 1.) showed the high degradation potential (88.34 per cent) of St. cacaoi subsp.asoensis (K234). Streptomyces luteogriseus (K144) and St. rimosus (K145) strains had 80 per cent degradation values, but biodetoxification was not detected by SOS-Chromotest, since induction factor were above 1.5 . 
Table 1

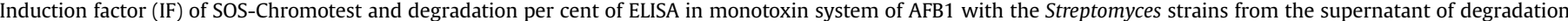

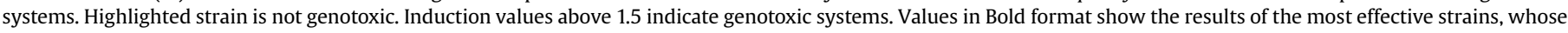
ELISA was measured with three replicates separately, (mean values $\pm S D, n=3$ ).

\begin{tabular}{|c|c|c|c|c|}
\hline Strains & Species & SOS Chromo test (IF) & ELISA AFB1 (ppm) & ELISA AFB1 (degradation per cent) \\
\hline K234 & St. cacaoi subsp.asoensis & $1.37 \pm 0.26$ & $0.132 \pm 0.177$ & $88.34 \pm 15.62$ \\
\hline K116 & St. baarnensis & $2.34 \pm 0.06$ & 0.627 & 50.90 \\
\hline K128 & St. spiroverticillatus & $2.30 \pm 0.32$ & 1.120 & 1.60 \\
\hline K129 & St. violarus & $2.23 \pm 0.31$ & 0.613 & 52.33 \\
\hline K136 & St. violaceoruber & $1.86 \pm 0.35$ & 1.088 & 4.79 \\
\hline K139 & St. sanglieri & $2.20 \pm 0.04$ & 0.522 & 61.43 \\
\hline K144 & St. luteogriseus & $1.76 \pm 0.25$ & 0.337 & 79.93 \\
\hline K145 & St. rimosus & $1.83 \pm 0.07$ & 0.337 & 79.93 \\
\hline K189 & St. rimosus & $2.14 \pm 0.08$ & 0.455 & 68.13 \\
\hline K236 & St. cinereoruber & $2.04 \pm 0.14$ & 0.551 & 58.52 \\
\hline Control & & $2.25 \pm 0.18$ & $1.136 \pm 0.129$ & 0.00 \\
\hline
\end{tabular}

\subsection{ZON biodegrading potential by the results of monotoxin degradation method}

Biological efficiency of ZON biodegradation of the ten selected strains was investigated with BLYES method and estrogenicity of the samples was indicated with bioluminescence intensification in percent. Immunoanalytical measurements of ZON were also performed with ELISA. Toxin degradation was calculated according to the remained mycotoxin concentration comparing to the controls.

The mean of bioluminescence intensification in percent (Table 2) of five strains (K136, K139, K145, K189, K234) was lower than the values of control samples (610 per cent BI). Two strains Streptomyces violaceoruber, and Streptomyces sanglieri (K136, K139) had slightly lower values than the control system. Intensification per cent of St. cacaoi subsp.asoensis (K234) strain was measured half as high as the control. The lowest BI values appeared at the strains St. rimosus (K145) and (K189). These two strains had also the highest degradation per cent values. In addition, for the strains St. spiroverticillatus (K128) and St. luteogriseus (K144), biodegradation values were measured at more than seventy per cent but the estrogenic effect remained. For strains St. baarnensis (K116) and St. spiroverticillatus (K128), besides the high degradation per cent values, estrogenic effect was higher than for the control system.

\subsection{Analysis of pellet}

Pellet fractions of the selected effective degrading strains were analyzed with ELISA in triplicates. Pellet analysis was performed with the most effective degrading strains (K128, K144, K145, K189, K234). None of the strains showed high amount of toxin absorption on the surface of the cell (Table 3). The lowest toxin concentration for AFB1 systems was detected at the strain with the most effective degradation potential, Streptomyces cacaoi subsp. asoensis (K234).
The strain St rimosus (K145) was detected to absorb AFB1 with the highest effectiveness. The highest absorbance of ZON molecules was detected for the strain St. luteogriseus (K144) with about 10 per cent. No absorbance was detected on the pellet in samples of the two strains with the most effective ZON degradation potential St. rimosus (K145, K189).

Results of pellet analysis showed negligible ZON absorbance on the pellet. This phenomenon was confirmed by experiments applying heat inactivated cells. Similar hormonal effects for the control and inactive cell systems indicate that ZON molecules do not bind to cell walls. Most of the investigated strains showed similar BI values to the control system (Table 4). Only for the strain St. cacaoi subsp.asoensis (K234), the intensification per cent was significantly lower than for the control system.

\section{Discussion}

In our study, mycotoxins (AFB1 and ZON) biodegradation potential of one hundred and twenty-three different species of Streptomyces genus from a collection of three hundred and eighty-four Streptomyces strains were analyzed. Ten strains with the highest detoxifying potential were selected for further investigations. Previous methods for preventing mycotoxicosis mainly focused on degradation of the mycotoxins or inhibition of the toxin producer fungi. In our study, beyond the biodegradation, biodetoxification efficiency of Streptomyces strains was also monitored.

Recently, Streptomyces strains have been also applied in detoxification processes against mycotoxins in several ways. Some studies revealed only the antagonist effects of Streptomyces strains against toxin producing fungi (Yekkour et al., 2012). According to Verheecke et al. (2014), Streptomyces strains inhibited AFB1 production in A. flavus by gene repression. Several Actinomycetes strains were revealed to be able to degrade directly mycotoxins. AFB1 (Cserháti

Table 2

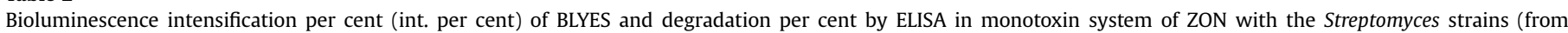
supernatant).

\begin{tabular}{|c|c|c|c|c|}
\hline Strains & Species & BLYES (int per cent) & ELISA ZON (ppm) & ELISA ZON (degradation per cent) \\
\hline K145 & St. rimosus & $-29.72 \pm 5.27^{* *}$ & $0.0035 \pm 0.0017^{*}$ & $99.62 \pm 0.18^{*}$ \\
\hline K189 & St. rimosus & $-30.14 \pm 7.36^{* *}$ & $0.0033 \pm 0.0022^{*}$ & $99.64 \pm 0.23^{*}$ \\
\hline K234 & St. cacaoi subsp.asoensis & $307.61 \pm 142.99^{* *}$ & $0.1125 \pm 0.0619 *$ & $87.85 \pm 6.68^{*}$ \\
\hline K116 & St. baarnensis & $710.67 \pm 31.50$ & 0.4200 & 55.13 \\
\hline K128 & St. spiroverticillatus & $687.74 \pm 119.49$ & 0.2245 & 76.01 \\
\hline K129 & St. violarus & $610.42 \pm 23.26$ & 0.6040 & 35.47 \\
\hline K136 & St. violaceoruber & $553.46 \pm 71.52$ & 0.3965 & 57.64 \\
\hline K139 & St. sanglieri & $478.35 \pm 41.85$ & 0.4330 & 53.74 \\
\hline K144 & St. luteogriseus & $665.16 \pm 25.44$ & 0.2555 & 72.70 \\
\hline K236 & St. cinereoruber & $708.22 \pm 62.17$ & 0.4555 & 50.84 \\
\hline Control & & $610.27 \pm 61.49$ & $0.9265 \pm 0.0602^{*}$ & $0.00 \pm 0.00^{*}$ \\
\hline
\end{tabular}

* For control and the most effective strains, ELISA was measured with three replicates separately, $($ mean values \pm SD, $n=3)$.

**Significant difference from Control values (one-way ANOVA, $\mathrm{F}_{10,22}=49.46 ; \mathrm{p}<<0.001$ ). 
Table 3

Degradation percent of ELISA (pellets) in monotoxin system of AFB1and ZON with the most effective toxin (AFB1 or ZON) degrading Streptomyces strains.

\begin{tabular}{|c|c|c|c|c|c|}
\hline Strains & Species & ELISA AFB1 pellet (ppm) & ELISA AFB1 pellet absorbance per cent & ELISA ZON pellet (ppm) & ELISA ZON pellet absorbance per cent \\
\hline K128 & St. spiroverticillatus & - & - & $0.0862 \pm 0.0367$ & $8.6 \pm 3.7$ \\
\hline K144 & St. luteogriseus & $0.1461 \pm 0.0737$ & $14.6 \pm 7.4$ & $0.1074 \pm 0.0199$ & $10.7 \pm 2.0$ \\
\hline K145 & St. rimosus & $0.2214 \pm 0.0787$ & $22.1 \pm 7.9$ & $0.0000 \pm 0.0000$ & $0.0 \pm 0.0$ \\
\hline K189 & St. rimosus & - & - & $0.0000 \pm 0.0000$ & $0.0 \pm 0.0$ \\
\hline K234 & St. cacaoi subsp.asoensis & $0.0508 \pm 0.0568$ & $5.1 \pm 5.7$ & $0.0648 \pm 0.0307$ & $6.5 \pm 3.1$ \\
\hline
\end{tabular}

Table 4

Bioluminescence intensification per cent of BLYES of the supernatant samples with autoclaved cells. (Mean and standard deviation values, $\mathrm{n}=3$ ).

\begin{tabular}{lll}
\hline Strains & Species & Intensification percent \\
\hline K234 & St. cacaoi subsp.asoensis & $435.9 \pm 36.6$ \\
K144 & St. luteogriseus & $638.2 \pm 35.3$ \\
K145 & St. rimosus & $693.4 \pm 103.6$ \\
K189 & St. rimosus & $729.0 \pm 15.4$ \\
K128 & St. spiroverticillatus & $770.7 \pm 72.0$ \\
Control & & $\mathbf{7 0 2 . 3} \pm \mathbf{5 5 . 6}$ \\
\hline
\end{tabular}

et al., 2013; Eshelli et al., 2015; Krifaton et al., 2011) and ZON (Cserháti et al., 2013; Krifaton et al., 2013) were reported to be degraded effectively by Streptomyces and Rhodococcus strains also.

In the present study, elimination of genotoxicity was detected in the case of AFB1 by SOS Chromotest and in the case of ZON estrogenic effect was measured by BLYES. These tests are cost-effective tools in the screening of mycotoxin-degrading bacteria (Krifaton et al., 2011, 2013). Besides testing biological effects, degradation of toxins was also monitored.

By the results of our study St. cacaoi subsp.asoensis strain (K234) had the highest AFB1 degrading potential which was proved both by SOS-Chromotest and ELISA in parallel.

Cserháti et al. (2013) and Krifaton et al. (2011) also conducted mycotoxin biodegrading analysis with Rhodococcus strains and they also measured high degradation of AFB1 and the loss of genotoxicity, like in the present work with St. cacaoi subsp. asoensis (K234). It means that this strain had high potential to eliminate genotoxicity of AFB1. However, the strain Streptomyces cinereoruber (K236) had high potential for degrading AFB1 but the genotoxicity remained high in the systems. It indicates that harmful metabolites may be produced during the degradation. Therefore, besides measuring degradation potential, testing biological effects is an essential step in eliminating toxins.

Biodegradation of ZON without creating harmful metabolites has been reported by several prokaryotic species (e.g. Yu et al., 2011). According to our results, ZON degrading capacity of the St. rimosus strains (K189 and K145) reached almost 100 per cent. In addition, the BLYES showed that these strains ceased the hormonal (estrogenic) effect of ZON. This degrading potential exceeded the degrading values of the Aspergillus niger FS10 strain in the experiment of Sun et al. (2014) and the values of the representatives of some Rhodococcus species in the study of Cserháti et al. (2013). However, our high degrading potential values were similar to the results of other Rhodocoocus strains in the study of Krifaton et al. (2013). Megharaj et al. (1997) measured similar degradation capacities in the case of a Pseudomonas fluorescens strain but they did not test the biological effects. For the strains St. baarnensis (K116) and St. spiroverticillatus (K128), estrogenic effect was similar to the control system besides high degradation potential. It indicates, similarly to the strain St. cinereoruber (K236) for AFB1-degradation, that harmful by-products were produced during degradation.

According to the pellet analyses, it can be verified that, high potentials of biodegradation occurred not due to absorption of mycotoxins on cell walls. In the case of St. rimosus (K189 and K145) strains, no ZON residues were detected, and for the St. cacaoi subsp. asoensis (K234), less than 10 per cent aflatoxin-B1 was detected in the pellet fraction. However, for the strain St. cacaoi subsp. asoensis (K234), high ZON degradation and low bioluminescence intensification per cent values were detected. The low estrogenic effect of $S t$. cacaoi subsp. asoensis (K234) was similar to the BI values of St. violaceoruber (K136) which strain had lower degradation potential. The analysis with inactive cells of St. cacaoi subsp. asoensis (K234) showed that this lower estrogenic effect was caused by absorption. The other strains with high ZON degradation potential showed low pellet absorption. Therefore, toxin concentration did not decrease due to the absorption so, presumably, bacterial strains were able to degrade mycotoxins with their enzymes and toxin content, except for the strain St. cacaoi subsp. asoensis (K234).

\section{Conclusion}

In the present study, several Streptomyces strains were successfully selected from one hundred and twenty-four strains and proved to be effective in the biodegradation of AFB1 and ZON mycotoxins. For biotechnological utilization, high toxin degradation potential is not sufficient to reach detoxification, since byproducts may cause additional toxicity. High degradation potential was detected besides the elimination of genotoxic and hormonal effects. Therefore, we could agree that the monitoring of biological effects after biodegradation is a very important part of detoxification analyses (Cserháti et al., 2013).

Many Streptomyces strains are used in biotechnological or pharmaceutical industry due to their high antibiotic producing capacity (Hashimoto et al., 2011). To date, Streptomyces strains have been investigated mainly for their antibiotic producing abilities. However, due to antibiotics production, Streptomyces strains cannot be used in biodegradation methods as a member of inocula, but according to our results, producing toxin degrading enzymes by these Streptomyces strains might be promising tools in decreasing economic and health damages caused by mycotoxins. The culture collection contained ten St. rimosus strains but in this experiment, only two strains were investigated which were the most effective degrading strains. Therefore, further experiments should be conducted on these other eight strains.

\section{Acknowledgments}

This project was supported by the Bioklíma KTIA-AIK_12-1-20130017 project, Aquafuture VKSZ-12-1-2013-0078 and Research Centre of Excellence-9878/2015/FEKUT. The author thanks for the BLYES bioreporters The University of Tennessee, Knoxville, Tennessee.

\section{Appendix A}

Contains the one hundred and twenty-four identified Streptomyces strains. Blue highlighting shows the ten most effective species which were used in the monotoxin experiment. The same concentration values of control systems indicate the strain groups which belonged to the same experiment. 


\begin{tabular}{|c|c|c|c|c|c|c|}
\hline No. & Strain & Identified species & $\begin{array}{l}\text { AFB1 SOS } \\
\text { CHROMO } \\
\text { (IF) }\end{array}$ & $\begin{array}{c}\text { Control SOS } \\
\text { CHROMO }\end{array}$ & $\begin{array}{c}\text { ZEA } \\
\text { BLYES } \\
\text { (BI) }\end{array}$ & $\begin{array}{l}\text { Control } \\
\text { BLYES }\end{array}$ \\
\hline 1. & K14 & Streptomyces cavourensis & 1.72 & 2.65 & 463.50 & 707.60 \\
\hline 2. & K15 & Streptomyces albus & 2.20 & 2.26 & 745.61 & 744.81 \\
\hline 3. & K18 & Streptomyces fradiae & 2.99 & 2.26 & 722.70 & 718.90 \\
\hline 4. & K25 & Streptomyces djakartensis & 1.31 & 2.65 & 383.20 & 707.60 \\
\hline 5. & K27 & Streptomyces antibioticus & 1.28 & 2.65 & 219.00 & 707.60 \\
\hline 6. & K28 & Streptomyces galilaeus & 1.98 & 2.65 & 620.90 & 707.60 \\
\hline 7. & K30 & Streptomyces tauricus & 2.49 & 2.65 & 252.20 & 707.60 \\
\hline 8. & K32 & Streptomyces tanashiensis & 3.24 & 3.33 & 665.85 & 681.26 \\
\hline 9. & K35 & Streptomyces albovinaceus & 1.18 & 2.65 & 356.70 & 707.60 \\
\hline 10. & K36 & Streptomyces turgidiscabies & 1.58 & 3.33 & 696.44 & 681.26 \\
\hline 11. & K40 & Streptomyces mutomycini & 1.00 & 3.33 & 806.15 & 681.26 \\
\hline 12. & K41 & Streptomyces viridochromogenes & 1.65 & 2.65 & 615.50 & 707.60 \\
\hline 13. & K43 & Streptomyces microflavus & 2.54 & 2.65 & 346.70 & 707.60 \\
\hline 14. & K44 & Streptomyces gancidicus & 1.14 & 2.65 & 543.60 & 707.60 \\
\hline 15. & K45 & Streptomyces rishiriensis & 1.36 & 2.65 & 148.70 & 707.60 \\
\hline 16. & K46 & Streptomyces thermocarboxydus & 1.13 & 2.65 & 679.20 & 707.60 \\
\hline 17. & K47 & Streptomyces europaeiscabiei & 2.37 & 2.65 & 419.70 & 707.60 \\
\hline 18. & K49 & Streptomyces griseobrunneus & 1.34 & 2.65 & 471.10 & 707.60 \\
\hline 19. & K51 & Streptomyces lohii & 1.27 & 2.65 & 729.90 & 707.60 \\
\hline 20. & K53 & Streptomyces flavogriseus & 0.90 & 2.26 & 683.90 & 718.90 \\
\hline 21. & K57 & Streptomyces rutgersensis & 0.96 & 2.26 & 746.22 & 744.81 \\
\hline 22. & K58 & Streptomyces laceyi & 1.19 & 2.65 & 310.90 & 707.60 \\
\hline 23. & K68 & Streptomyces anulatus & 1.63 & 2.65 & 624.30 & 707.60 \\
\hline 24. & K73 & Streptomyces baliensis & 1.50 & 2.65 & -31.34 & 707.60 \\
\hline 25. & K74 & Streptomyces gougerotii & 1.16 & 2.65 & 419.70 & 707.60 \\
\hline 26. & K75 & Streptomyces rutgersensis & 1.44 & 2.65 & 630.60 & 707.60 \\
\hline 27. & K76 & Streptomyces flavolimosus & 1.17 & 2.65 & 596.80 & 707.60 \\
\hline 28. & K77 & Streptomyces drozdowiczii & 1.64 & 2.65 & 269.50 & 707.60 \\
\hline 29. & K78 & Streptomyces sampsonii & 1.11 & 2.65 & 385.20 & 707.60 \\
\hline 30. & K93 & Streptomyces albus subsp. Albus & 2.02 & 2.26 & 770.69 & 744.81 \\
\hline 31. & K96 & Streptomyces minoensis & 1.42 & 2.65 & 165.50 & 707.60 \\
\hline 32. & K100 & Streptomyces gibsonii & 2.11 & 2.26 & 523.70 & 718.90 \\
\hline 33. & K101 & Sterptomyces wedmorensis & 1.48 & 2.65 & 212.90 & 707.60 \\
\hline 34. & K102 & Streptomyces olivochromogenes & 1.38 & 2.65 & 440.00 & 707.60 \\
\hline 35. & K103 & Streptomyces rangoonensis & 3.70 & 3.33 & 739.68 & 681.26 \\
\hline 36. & K106 & Streptomyces rubiginosohelvolus & 1.27 & 2.65 & 253.40 & 707.60 \\
\hline 37. & K108 & Streptomyces cyaneofuscatus & 1.17 & 2.65 & 98.80 & 707.60 \\
\hline 38. & K109 & Streptomyces xanthochromogenes & 1.93 & 3.33 & 716.68 & 681.26 \\
\hline 39. & K113 & Streptomyces violascens & 2.41 & 3.33 & 837.89 & 681.26 \\
\hline 40. & K116 & Streptomyces baarnensis & 0.99 & 3.78 & 24.10 & 760.14 \\
\hline 41. & K123 & Streptomyces ciscaucasicus & 1.33 & 2.26 & 536.48 & 744.81 \\
\hline 42. & K125 & Streptomyces spectabilis & 2.28 & 3.33 & 649.06 & 681.26 \\
\hline 43. & K128 & Streptomyces spiroverticillatus & 0.91 & 3.78 & 4.00 & 760.14 \\
\hline 44. & K129 & Streptomyces violarus & 0.98 & 3.78 & 22.60 & 760.14 \\
\hline 45. & K130 & Streptomyces yokosukanensis & 1.12 & 3.78 & 163.60 & 760.14 \\
\hline 46. & K130 & Streptomyces halstedii & 1.12 & 2.26 & 485.60 & 718.90 \\
\hline 47. & K132 & Streptomyces glomeroaurantiacus & 1.01 & 3.78 & 66.50 & 760.14 \\
\hline 48. & K135 & Streptomyces tendae & 0.94 & 3.78 & 46.70 & 760.14 \\
\hline 49. & K136 & Streptomyces violaceoruber & 0.95 & 3.78 & 13.80 & 760.14 \\
\hline
\end{tabular}


P. Harkai et al. / International Biodeterioration E Biodegradation 108 (2016) 48-56

\begin{tabular}{|c|c|c|c|c|c|c|}
\hline No. & Strain & Identified species & $\begin{array}{c}\text { AFB1 SOS } \\
\text { CHROMO } \\
\text { (IF) }\end{array}$ & $\begin{array}{l}\text { Control SOS } \\
\text { CHROMO }\end{array}$ & $\begin{array}{c}\text { ZEA } \\
\text { BLYES } \\
\text { (BI) }\end{array}$ & $\begin{array}{l}\text { Control } \\
\text { BLYES }\end{array}$ \\
\hline 50. & K138 & Streptomyces althioticus & 1.74 & 2.26 & 749.76 & 744.81 \\
\hline 51. & K139 & Streptomyces sanglieri & 0.99 & 3.78 & 21.20 & 760.14 \\
\hline 52. & K144 & Streptomyces luteogriseus & 0.94 & 3.78 & 14.10 & 760.14 \\
\hline 53. & K145 & Streptomyces rimosus & 0.96 & 3.78 & -3.60 & 760.14 \\
\hline 54. & K153 & Streptomyces violaceorubidus & 2.03 & 3.33 & 637.79 & 681.26 \\
\hline 55. & K156 & Streptomyces atratus & 0.96 & 3.78 & 44.00 & 760.14 \\
\hline 56. & K170 & Streptomyces canus & 1.51 & 2.26 & 451.17 & 744.81 \\
\hline 57. & K171 & Streptomyces lincolnensis & 0.98 & 3.78 & 69.00 & 760.14 \\
\hline 58. & K173 & Streptomyces lateritius & 1.10 & 2.26 & 686.90 & 718.90 \\
\hline 59. & K176 & Streptomyces caniferus & 0.92 & 3.78 & 49.80 & 760.14 \\
\hline 60. & K178 & Streptomyces bottropensis & 1.24 & 2.26 & 330.36 & 744.81 \\
\hline 61. & K179 & Streptomyces setonii & 3.23 & 3.33 & 770.27 & 681.26 \\
\hline 62. & K181 & Streptomyces gardneri & 1.36 & 2.26 & 749.50 & 718.90 \\
\hline 63. & K189 & Streptomyces rimosus & 0.91 & 3.78 & 15.20 & 760.14 \\
\hline 64. & K191 & Streptomyces flavovirens & 1.02 & 3.78 & 118.40 & 760.14 \\
\hline 65. & K197 & Streptomyces violaceolatus & 1.01 & 3.78 & 73.40 & 760.14 \\
\hline 66. & K201 & Streptomyces caeruleatus & 1.02 & 3.78 & 127.80 & 760.14 \\
\hline 67. & K202 & Streptomyces pilosus & 1.00 & 3.78 & 57.70 & 760.14 \\
\hline 68. & K204 & Streptomyces cirratus & 0.95 & 3.78 & 84.10 & 760.14 \\
\hline 69. & K205 & Streptomyces cellulosae & 1.51 & 2.26 & 683.30 & 744.81 \\
\hline 70. & K225 & Streptomyces cinnamonensis & 1.19 & 2.26 & 998.65 & 744.81 \\
\hline 71. & K228 & Streptomyces viridodiastaticus & 0.98 & 3.78 & 100.10 & 760.14 \\
\hline 72. & K232 & Streptomyces finlayi & 1.01 & 3.78 & 27.60 & 760.14 \\
\hline 73. & K233 & Streptomyces humidus & 0.97 & 3.78 & 142.10 & 760.14 \\
\hline 74. & K234 & Streptomyces cacaoi subsp.asoensis & 0.95 & 3.78 & 3.10 & 760.14 \\
\hline 75. & K236 & Streptomyces cinereoruber & 0.94 & 3.78 & 22.40 & 760.14 \\
\hline 76. & K237 & Streptomyces litmocidini & 2.34 & 2.26 & 735.20 & 718.90 \\
\hline 77. & K238 & Streptomyces olivaceoviridis & 1.00 & 3.78 & 46.10 & 760.14 \\
\hline 78. & K242 & Streptomyces albidoflavus & 0.94 & 3.78 & 63.10 & 760.14 \\
\hline 79. & K244 & Streptomyces xanthophaeus & 3.10 & 3.33 & 637.56 & 681.26 \\
\hline 80. & K245 & Streptomyces sporoverrucosus & 1.18 & 3.33 & 472.65 & 681.26 \\
\hline 81. & K251 & Streptomyces lavendulae & 1.76 & 2.26 & 844.50 & 718.90 \\
\hline 82. & K253 & Streptomyces umbrinus & 1.02 & 3.78 & 83.60 & 760.14 \\
\hline 83. & K254 & Streptomyces vinaceus & 0.97 & 3.33 & -24.84 & 681.26 \\
\hline 84. & K256 & Streptomyces cinereorectus & 1.24 & 2.26 & 798.16 & 744.81 \\
\hline 85. & K265 & Streptomyces seoulensis & 3.28 & 3.33 & 639.86 & 681.26 \\
\hline 86. & K269 & Streptomyces cacaoi subsp. Cacaoi & 1.16 & 2.26 & 641.84 & 744.81 \\
\hline 87. & K271 & Streptomyces diastaticus & 2.66 & 3.33 & 720.36 & 681.26 \\
\hline 88. & K272 & Streptomyces rubrogriseus & 2.02 & 3.33 & 727.26 & 681.26 \\
\hline 89. & K278 & $\begin{array}{l}\text { Streptomyces cinereoruber } s . \\
\text { fructofermentans }\end{array}$ & 1.64 & 2.26 & 575.40 & 744.81 \\
\hline 90. & K293 & Streptomyces mutabilis & 3.26 & 3.33 & 631.35 & 681.26 \\
\hline 91. & $k 296$ & Streptomyces decoyicus & 3.43 & 3.33 & 564.65 & 681.26 \\
\hline 92. & K305 & Streptomyces coelicoflavus & 2.29 & 2.26 & 819.17 & 744.81 \\
\hline 93. & K312 & Streptomyces albolongus & 1.72 & 2.26 & 795.89 & 744.81 \\
\hline 94. & K315 & Streptomyces longwoodenesis & 1.63 & 2.26 & 613.60 & 718.90 \\
\hline 95. & K321 & Streptomyces geysirinesis & 2.32 & 2.26 & 754.90 & 718.90 \\
\hline 96. & K331 & Streptomyces viridochromogenes & 1.03 & 3.78 & 87.50 & 760.14 \\
\hline 97. & K333 & Streptomyces kanamyceticus & 1.03 & 2.26 & 412.60 & 718.90 \\
\hline 98. & K340 & Streptomyces albogriseolus & 1.78 & 2.26 & 590.94 & 744.81 \\
\hline 99. & K341 & Streptomyces griseoaurantiacus & 2.40 & 2.26 & 553.20 & 718.90 \\
\hline
\end{tabular}




\begin{tabular}{|l|l|c|c|c|c|c|}
\hline No. & Strain & Identified species & $\begin{array}{c}\text { AFB1 SOS } \\
\text { CHROMO } \\
\text { (IF) }\end{array}$ & $\begin{array}{c}\text { Control SOS } \\
\text { CHROMO }\end{array}$ & $\begin{array}{c}\text { ZEA } \\
\text { BLYES } \\
\text { (BI) }\end{array}$ & $\begin{array}{c}\text { Control } \\
\text { BLYES }\end{array}$ \\
\hline 100. & K352 & Streptomyces yanii & 3.64 & 3.33 & 620.31 & 681.26 \\
\hline 101. & K360 & Streptomyces phaeoluteigriseus & 1.75 & 3.33 & 736.92 & 681.26 \\
\hline 102. & K371 & Streptomyces phaeofaciens & 1.52 & 3.33 & 787.06 & 681.26 \\
\hline 103. & K374 & Streptomyces diastaticus subs. Ardesiacus & 1.98 & 2.26 & 19.40 & 718.90 \\
\hline 104. & K391 & Streptomyces coelescens & 1.84 & 2.26 & 767.40 & 744.81 \\
\hline 105. & K397 & Streptomyces collinus & 1.46 & 2.26 & 642.13 & 744.81 \\
\hline 106. & K398 & Streptomyces bungoensis & 1.20 & 2.26 & 453.60 & 744.81 \\
\hline 107. & K403 & Streptomyces marokkonensis & 2.11 & 2.26 & 894.10 & 718.90 \\
\hline 108. & K405 & Streptomyces massasporeus & 1.28 & 2.26 & 455.00 & 718.90 \\
\hline 109. & K407 & Streptomyces matensis & 2.09 & 2.26 & 798.10 & 718.90 \\
\hline 110. & K409 & Streptomyces prasinus & 1.18 & 3.33 & 651.59 & 681.26 \\
\hline 111. & K418 & Streptomyces exfoliatus & 1.10 & 2.26 & 864.20 & 718.90 \\
\hline 112. & K419 & Streptomyces phaeochromogenes & 1.51 & 3.33 & 503.7 & 681.26 \\
\hline 113. & K425 & Streptomyces badius & 1.33 & 2.26 & 852.80 & 744.81 \\
\hline 114. & K434 & Streptomyces flavidovirens & 2.04 & 2.26 & 898.30 & 718.90 \\
\hline 115. & K436 & Streptomyces hydrogenans & 1.53 & 2.26 & 626.30 & 718.90 \\
\hline 116. & K447 & Streptomyces fulvorobeus & 1.89 & 2.26 & 771.50 & 718.90 \\
\hline 117. & K448 & Streptomyces griseorubiginosus & 1.19 & 2.26 & 774.60 & 718.90 \\
\hline 118. & K450 & Streptomyces speiboane & 3.36 & 3.33 & 657.34 & 681.26 \\
\hline 119. & K456 & Streptomyces intermedius & 1.64 & 2.26 & 750.80 & 718.90 \\
\hline 120. & K460 & Streptomyces griseus subsp. Griseus & 1.04 & 2.26 & 674.30 & 718.90 \\
\hline 121. & K473 & Streptomyces globisporus & 2.56 & 2.26 & 1090.60 & 718.90 \\
\hline 122. & K486 & Streptomyces omiyaensis & 2.47 & 3.33 & 839.51 & 681.26 \\
\hline 123. & K489 & Streptomyces prunicolor & 3.39 & 3.33 & 690.23 & 681.26 \\
\hline 124. & K490 & Streptomyces flaveolus & 2.05 & 2.26 & 573.90 & 718.90 \\
\hline & & & & & & \\
\hline
\end{tabular}

hundred and twenty-four Streptomyces strains ten Streptomyces were chosen about they biodegradation ability (AFB1, ZEA) red marking: above 1.5 IF value (AFB1 degradation)

\section{References}

Altalhi, A.D., 2007. Plasmid-inediated detoxification of mycotoxin zearalenone in Pseudomonas sp. ZEA-1. Am. J. Biotechnol. Biochem. 3, 150-158.

Bennett, J.W., Klich, M., 2003. Mycotoxins. Clin. Microbiol. Rev. 16, 497-516.

Berek, L., Petri, I.B., Mesterhazy, A., Téren, J., Molnár, J., 2001. Effects of mycotoxins on human immune functions in vitro. Toxicol. in vitro 15, 25-30.

Cserháti, M., Kriszt, B., Krifaton, C., Szoboszlay, S., Háhn, J., Tóth, S., Nagy, I., Kukolya, J., 2013. Mycotoxin-degradation profile of Rhodococcus strains. Int. J. Food Microbiol. 166, 176-185.

Eaton, D.L., Ramsdell, H.S., Neal, G.E., 1994. Biotransformation of aflatoxins. In: Eaton, D.L., Groopmann, J.D. (Eds.), The Toxicology of Aflatoxins. Academic Press, San Diego, CA, pp. 45-72.

Ehrlich, V., Darroudi, F., Uhl, M., Steinkellner, H., Gann, M., Majer, B.J., Eisenbauer, M. Knasmüller, S., 2002. Genotoxic effects of ochratoxin A in human-derived hepatoma (HepG2) cells. Food Chem. Toxicol. 40, 1085-1090.

El-Sharkawy, S., Abul-Hajj, Y., 1987. Microbial transformation of zearalenone, I. Formation of zearalenone-4-O- $\beta$-glucoside. J. Nat. Prod 50 (3), 520-521.

Eshelli, M., Harvey, L., Edrada-Ebel, R., McNeil, B., 2015. Metabolomics of the biodegradation process of aflatoxin B1 by Actinomycetes at an initial pH of 6.0. Toxins 7, 439-456.

Farnworth, E.R., Trenholm, H.L., 1983. The metabolism of the mycotoxin zearalenone and its effects on the reproductive tracts of young male and female pigs. Can. J. Anim. Sci. 63, 967-975.
Froehner, K., Meyer, W., Grimme, L.H., 2002. Time-dependent toxicity in the longterm inhibition assay with Vibrio fischeri. Chemosphere 46, 987-997.

Green, M.L., Diekman, M.A., Malayer, J.R., Scheidt, A.B., Long, G.G., 1990. Effect of prepubertal consumption of zearalenone on puberty and subsequent. J. Anim. Sci. $68,171-178$.

Hashimoto, M., Katsura, H., Kato, R., Kawaide, H., Natsume, M., 2011. Effect of pamamycin-607 on secondary metabolite production by Streptomyces sp. Biosci. Biotechnol. Biochem. 75, 1722-1726.

Hormisch, D., Brost, I., Kohring, G.W., Giffhorn, F., Kroppenstedt, R.M., Stackebradt, E., Farber, P., Holzapfel, W.H., 2004. Mycobacterium fluoranthenivorans $s p$. nov., a fluoranthene and aflatoxin B 1 degrading bacterium from contaminated soil of a former coal gas plant. Syst. Appl. Microbiol. 27, 653-660.

Hughes, C.L., Chakinala, M.M., Reece, S.G., Miller, R.N., Schomberg, D.W., Basham, K.B., 1991. Acute and subacute effects of naturally occurring estrogens on luteinizing hormone secretion in the ovariectomized rat: part 2. Reprod. Toxicol. 5, 133-137.

Hussein, H.S., Brasel, J.M., 2001. Toxicity, metabolism, and impact of mycotoxins on humans and animals. Toxicology 167, 101-134.

Krifaton, C., Kriszt, B., Szoboszlay, S., Cserháti, M., Szűcs, Á., Kukolya, J., 2011. Analysis of aflatoxin-B1-degrading microbes by use of a combined toxicityprofiling method. Mutat. Res./Genet. Toxicol. Environ. Mutagen. 726, 1-7.

Krifaton, C., Kriszt, B., Risa, A., Szoboszlay, S., Cserháti, M., Harkai, P., Eldridge, M., Wang, J., Kukolya, J., 2013. Application of a yeast estrogen reporter system for 
screening zearalenone degrading microbes. J. Hazard. Mater. 244, 429-435.

Kriszt, R., Krifaton, Cs., Szoboszlay, S., 2012. Cserháti M., Kriszt B., Kukolya J., Czéh Á. Fehér-Tóth Sz., Török L., Szőke Zs., Kovács K.J., Barna T., Ferenczi Sz., A new zearalenone biodegradation strategy using non-pathogenic. Rhodococcus pyridinivorans K408 strain PLoS One 7 (9).

Kurtzman, C.P., Horn, B.W., Hesseltine, C.W., 1987. Aspergillus nomius, a new aflatoxin-producing species related to Aspergillus flavus and Aspergillus tamarii. Antonie van Leeuwenhoek 53, 147-158.

Lemke, S.L., Grant, P.G., Phillips, T.D., 1998. Adsorption of zearalenone by organophilic montmorillonite clay. J. Agric. Food Chem. 46, 3789-3796.

McLean, M., Dutton, M.F., 1995. Cellular interactions and metabolism of aflatoxin: an update. Pharmacol. Ther. 65, 163-192.

Megharaj, M., Garthwaite, I., Thiele, J.H., 1997. Total biodegradation of the oestrogenic mycotoxin zearalenone by a bacterial culture. Lett. Appl. Microbiol. 24, 329-333.

Mishra, H.N., Das, C., 2003. A review on biological control and metabolism of aflatoxin. Crit. Rev. Food Sci. 43, 245-264.

Molnar, O., Schatzmayr, G., Fuchs, E., Prillinger, H., 2004. Trichosporon mycotoxinivorans sp. nov., a new yeast species useful in biological detoxification of various mycotoxins. Syst. Appl. Microbiol. 27, 661-671.

Panel, E.B., 2013. Scientific opinion on the maintenance of the list of QPS biological agents intentionally added to food and feed (2013 update). EFSA J. 11 (11), 3449.

Park, D.L., 1993. Perspectives on mycotoxin decontamination procedures. Food Addit. Contam. 10, 49-60.

Ramos, A.J., Fink-Gremmels, J., Hernández, E., 1996. Prevention of toxic effects of mycotoxins by means of nonnutritive adsorbent compounds. J. Food Prot. 59, 631-641.

Routledge, E.J., Sumpter, J.P., 1996. Estrogenic activity of surfactants and some of their degradation products assessed using a recombinant yeast screen. Environ. Toxicol. Chem. 15, 241-248.

Sakuda, S., Ono, M., Furihata, K., Nakayama, J., Suzuki, A., Isogai, A., 1996. Aflastatin A, a novel inhibitor of aflatoxin production of Aspergillus parasiticus, from Streptomyces. J. Am. Chem. Soc. 118, 7855-7856.

Sanseverino, I., Gupta, R.K., Layton, A.C., Patterson, S.S., Ripp, S.A., Saidak, L., Simpson, M.L., Schultz, T.W., Sayler, G.S., 2005. Use of Saccharomyces cerevisiae BLYES expressing bacterial bioluminescence for rapid, sensitive detection of estrogenic compounds. Appl. Environ. Microbiol. 71, 4455-4460.

Sharma, R.P., 1993. Immunotoxicity of mycotoxins. J. Dairy Sci. 76, 892-897.
Sun, X., He, X., Li, Y., Xu, D., Qian, H., 2014. Biological detoxification of zearalenone by Aspergillus niger strain FS10. Food Chem. Toxicol 72, 76-82.

Tanaka, T., Hasegawa, A., Yamamoto, S., Lee, U.S., Sugiura, Y., Ueno, Y., 1988 Worldwide contamination of cereals by the Fusarium mycotoxins nivalenol, deoxynivalenol, and zearalenone. 1. Survey of 19 countries. J. Agric. Food Chem. 36, 979-983.

Teniola, O.D., Addo, P.A., Brost, I.M., Färber, P., Jany, K.D., Alberts, J.F., Holzapfel, W.H. 2005. Degradation of aflatoxin B 1 by cell-free extracts of Rhodococcus erythropolis and Mycobacterium fluoranthenivorans sp. nov. DSM44556 T. Int. J. Food Microbiol. 105, 111-117.

Utermark, J., Karlovsky, P., 2007. Role of zearalenone lactonase in protection of Gliocladium roseum from fungitoxic effects of the mycotoxin zearalenone. Appl. Environ. Microbiol. 73, 637-642.

Varga, J., Péteri, Z., Tábori, K., Téren, J., Vágvölgyi, C., 2005. Degradation of ochratoxin A and other mycotoxins by Rhizopus isolates. Int. J. Food Microbiol. 99 $321-328$.

Verheecke, C., Liboz, T., Darriet, M., Sabaou, N., Mathieu, F., 2014. In vitro interaction of actinomycetes isolates with Aspergillus flavus: impact on aflatoxins B1 and B2 production. Lett. Appl. Microbiol. 58, 597-603.

Williams, J.H., Phillips, T.D., Jolly, P.E., Stiles, J.K., Jolly, C.M., Aggarwal, D., 2004 Human aflatoxicosis in developing countries: a review of toxicology, exposure, potential health consequences, and interventions. Am. J. Clin. Nutr. 80 1106-1122.

Withanage, G.S., Murata, H., Koyama, T., Ishiwata, I., 2001. Agonistic and antagonistic effects of zearalenone, an etrogenic mycotoxin, on SKN, HHUA, and HepG2 human cancer cell lines. Veterinary Hum. Toxicol. 43, 6-10.

Wu, F., 2004. Mycotoxin risk assessment for the purpose of setting international regulatory standards. Environ. Sci. And Technol. 38, 4049-4055.

Yekkour, A., Sabaou, N., Zitouni, A., Errakhi, R., Mathieu, F., Lebrihi, A., 2012. Characterization and antagonistic properties of Streptomyces strains isolated from Saharan soils, and evaluation of their ability to control seedling blight of barley caused by Fusarium culmorum. Lett. Appl. Microbiol. 55, 427-435.

Yu, Y., Qiu, L., Wu, H., Tang, Y., Yu, Y., Li, X., Liu, D., 2011. Degradation of zearalenone by the extracellular extracts of Acinetobacter sp. SM04 liquid cultures. Biodegradation 22 , 613-622.

Zucchi, T.D., De Moraes, L.A.B., De Melo, I.S., 2008. Streptomyces sp. ASBV-1 reduces aflatoxin accumulation by Aspergillus parasiticus in peanut grains. J. Appl. Microbiol. 105, 2153-2160. 